\title{
REGÍMENES DE ACUMULACIÓN CAPITALISTA: \\ UN ENFOQUE ESTRUCTURAL PARA ANALIZAR LA \\ ESTABILIDAD DE LA DEMOCRACIA (1945-2001)
}

\section{Accumulation Regimes: A Structural Approach to Analyze the Stability of Democracy (1945-2001)}

\section{FEDERICO TRAVERSA}

Universidad de la República, Uruguay

\begin{abstract}
RESUMEN
Hace cerca de cincuenta años, Lipset (1959) ligó el desarrollo económico capitalista con la expansión de la democracia. A partir del uso del concepto de regímenes de acumulación (Boyer, 2007) este trabajo intenta ofrecer una perspectiva diferente sobre esta relación. Se argumenta que sólo algunos regímenes de acumulación capitalista estuvieron asociados a la estabilidad democrática en el período 1945-2001, y esto debido a sus patrones especiales de distribución del ingreso, y a sus ritmos estables de expansión del producto. Además, aquí se evalúan los efectos de la distribución del ingreso sobre la estabilidad democrática, en forma novedosa. Primero, porque se abandona el uso del Teorema del Votante Mediano (Acemoglu y Robinson, 2006; Boix, 2003). Y segundo, porque para la exploración empírica no se utiliza el índice de Gini como variable independiente; en su lugar se construye una medida de polarización de ingresos (IED) que permite predecir en forma más eficiente la estabilidad democrática.
\end{abstract}

Palabras clave: Democracia, estabilidad, desarrollo económico, acumulación capitalista, distribución del ingreso.

\begin{abstract}
Fifty years ago, Lipset (1959) linked the capitalist economic development with the expansion of democracy. Using the concept of regimes of accumulation (Boyer, 2007) this paper attempts to offer a different perspective on this relationship. First, here I argue that only some regimes of capitalist accumulation were associated with democratic stability in the period 1945-2001; and only because of their special patterns of income distribution, and their stable rates of GDP growth. Further, the effects of income distribution on democratic stability are evaluated here in new ways. First, because the Median Voter Theorem is not used here (Acemoglu and Robinson, 2006; Boix, 2003). And second, because instead of using the Gini index as an independent variable, here I constructed a measure of income polarization (IED) that predict democratic stability more efficiently than the Gini index.
\end{abstract}

Key words: Democracy, stability, income distribution, capital accumulation, economic development. 


\section{INTRODUCCIÓN ${ }^{1}$}

Todos queremos ser ricos y vivir en democracia. Y razones no nos faltan. Vivir en un país rico significa mejores probabilidades de tener una vida saludable, de recibir educación, de disfrutar mayores comodidades. Vivir en un régimen democrático implica un gobierno que debe respetar al menos algunos derechos y libertades, y que responderá periódicamente por sus decisiones políticas. Lipset (1959) afirmó que ambos objetivos no sólo son posibles, sino complementarios, este es un supuesto fundamental de la llamada Teoría de la Modernización (TdM).

El sentido común parece sugerir que esta teoría debería ser cierta: ¿acaso no sería más fácil vivir en democracia si todos fuéramos más ricos? Por su parte, infinidad de estudios empíricos se han encargado de corroborar esta intuición: los países más ricos suelen ser democráticos, los más pobres autoritarios. Como afirman Acemoglu et al. (2008: 808): "una de las más notables regularidades en economía política, es la relación entre PBI per cápita y democracia". Luego, para muchos, esta correlación empírica parece convertirse en una buena noticia: si concentramos nuestro esfuerzo en ser ricos construiremos, por añadidura, una democracia estable, y así estaremos "matando dos pájaros de un tiro".

Sin embargo, a esta altura, algunas preguntas incómodas pueden surgir, quisiera enunciar dos. En primer lugar; si se registra una fuerte correlación entre desarrollo económico y democracia ¿quiere esto decir que el desarrollo económico es lo que hace a una democracia estable y duradera? Esta pregunta no es ociosa, porque las meras correlaciones han inspirado una de las más conocidas falacias: cum hoc, ergo propter hoc (que implica pensar que como dos cosas aparecen juntas, entonces una es la causa de la otra).

Respecto al problema de la correlación entre desarrollo económico y democracia, aquí se defenderá la siguiente posición: poco hay en el desarrollo económico per se, que asegure o facilite de las posibilidades de una convivencia democrática. Pero entonces, ¿cómo se explica la correlación existente entre ambos fenómenos? Antes que nada cabe remarcar que esta correlación parece sólo válida desde el siglo XX, previamente Occidente aumentó consistentemente su desarrollo económico por cientos de años, y no surgió la democracia.

Ya en el siglo XX, en cambio, el desarrollo económico propició patrones de distribución social del ingreso más favorables a la convivencia democrática. Por eso, desde hace décadas, el desarrollo ha estado asociado con la democracia. Sin embargo, la asociación está intermediada fuertemente por las pautas de distribución del ingreso como variable interviniente, y principal explicación del fenómeno.

1 Quiero agradecer especialmente los aportes que realizaron Daniel Buquet, Rafael Piñeiro y Sebastián Díaz López, así como las oportunas y pacientes sugerencias que dos árbitros anónimos hicieron al trabajo. De más está decir que todas las carencias que aún se restan en este trabajo, son responsabilidad de su autor. 
En términos estrictos no sería entonces el desarrollo lo que genera democracia, sino determinadas pautas de distribución del ingreso ${ }^{2}$ las que favorecen la estabilidad de la democracia. La distinción puede parecer vana, siempre que el desarrollo económico pareció favorecer estas pautas de distribución del ingreso en el siglo XX. Pero no lo es por dos razones. En primer lugar, porque no es necesario confundir un problema si conocemos que una respuesta es inexacta. Pero sobre todo, y en segundo lugar, porque tal vez no siempre el camino del desarrollo económico está asociado a esta distribución del ingreso que favorece la democracia.

Y aquí ingresa una segunda pregunta incómoda que ya anunciamos: aún aceptando que si fuéramos más ricos seríamos más democráticos, ¿todos los países pueden llegar a ser ricos, y el camino al enriquecimiento es también un proceso de paulatina democratización? Que los actuales ricos sean democráticos, no significa que todos puedan alcanzar ese "estado ideal", ni que el camino hasta llegar a este estado implique una democratización incremental y progresiva. De hecho, en ocasiones, parece que búsqueda del desarrollo económico erosiona las pautas de distribución del ingreso que favorecen la democracia.

Mientras tanto, el énfasis de la TdM en considerar al problema del desarrollo económico como único y central para el logro de una convivencia democrática, nos induce a olvidar el más importante y recurrente problema económico para la estabilidad democrática: la puja por la distribución del ingreso y por los recursos económicos en general. Estos conflictos por la distribución del ingreso son más frecuentes y difíciles de resolver en los países periféricos, donde hay menor margen para la negociación del problema. Y América Latina, con un proceso nunca acabado e irregular de democratización, es el ejemplo más notorio.

De ahí que el pensamiento latinoamericano haya sido particularmente activo para brindar perspectivas novedosas e interesantes sobre estos problemas (Prebisch 1967, Ferrer et al. 1984). Cardoso y Faletto (1969), abordan el problema del desarrollo con un enfoque estructural, que no deja lugar para "cabos sueltos". Desde su perspectiva, el desarrollo y el subdesarrollo son dos caras de una misma moneda, ${ }^{3}$ y la dependencia beneficia a algunos sectores sociales de la periferia, que llevan la mejor parte en la distribución del ingreso, y con frecuencia favorecen dinámicas políticas autoritarias.

A partir de ello, Guillermo O’Donnell (1982) desnudó notorias inconsistencias de la TdM, en sus estudios sobre las experiencias autoritarias del $C$ ono Sur latinoamericano, reunidas bajo la categoría de "Estados Burocrático-Autoritarios". Fueron justamente los países latinoamericanos de mayor desarrollo económico relativo, quienes sufrieron algunas de las más crueles dictaduras de la década del setenta, esto resulta incomprensible para la

2 Este trabajo busca justamente explicar en que consisten estas pautas de distribución del ingreso y porqué están ligadas a la estabilidad de la democracia. Asimismo se intentará ofrecer evidencia empírica de estas relaciones.

3 En sus propias palabras “de ahí que entre las economías desarrolladas y las subdesarrolladas no sólo exista una simple diferencia de etapa o de estado del sistema productivo, sino también una función o posición dentro de una misma estructura económica internacional de producción y distribución" (Cardoso y Faletto, 1969: 23). 
$\mathrm{TdM}$, que abandona toda perspectiva estructural del problema. Otros estudios posteriores de "n pequeño" han efectuado valiosos aportes, entre ellos uno de los más reconocidos es el de Rueschemeyer et al. (1992).

En los últimos años, como establecen Wucherpfennig y Deutsch (2009), la ciencia política ha vuelto a abordar relación entre el desarrollo económico y la democracia, y en ocasiones se ha volcado por analizar la distribución del ingreso como variable mediadora. Aportes valiosos como los de Acemoglu y Robinson (2005: 99-113) y Boix (2003: 23), utilizan al Teorema del Votante Mediano (TVM) como un insumo básico para evaluar los efectos de la distribución del ingreso sobre la democracia. ${ }^{4}$

Sin embargo, según distintos autores (Groemling, 2002) las aplicaciones del TVM a problemas redistributivos (Meltzer y Richards, 1981) por lo general ha mostrado magros resultados en el plano empírico. Este trabajo intentará ofrecer una perspectiva alternativa, para comprender la relación entre el desarrollo capitalista y la estabilidad de la democracia.

En primer lugar, se argumenta que la relación entre el desarrollo capitalista y la democracia no es directa, sino que está mediada por variables económicas intervinientes. Los países capitalistas más desarrollados muestran democracias más duraderas, gracias a que tienen ritmos estables de expansión del producto, y una distribución del ingreso donde los pobres no se encuentran polarizados. ${ }^{5}$ Ambos fenómenos disminuyen la ocurrencia de conflictos distributivos, y así se producen menos golpes de Estado, y la democracia es más estable (Esquemas II y III).

En segundo lugar, al analizar la influencia de las pautas de la distribución del ingreso sobre la estabilidad democrática, aquí no se le asigna un papel importante a la desigualdad en términos genéricos, sino más específicamente a la polarización de ingresos entre los sectores más pobres. Se llega a esta conclusión, a partir del desarrollo de un modelo que agrega dos supuestos plausibles al TVM: abstención por alienación (Hinich, 1997) y distribución asimétrica del ingreso.

En tercer lugar, y a consecuencia de lo anterior, se evalúan empíricamente los efectos de la polarización de ingresos sobre la duración de 65 regímenes democráticos en el período 1945-2001. Para ello se construyó un Índice de Estabilidad Distributiva, que arroja mayores valores, cuanto menor es la polarización de ingresos entre los más pobres. El resultado es que este nuevo índice permite predecir mejor la duración de la democracia que el índice de Gini, que es el más utilizado en la literatura sobre estos temas.

4 Tanto el desarrollo de Boix (2003) como el de Acemoglu (2006) suponen modelos afinados y complejos que incorporan una evaluación del papel de distintas variables económicas y políticas respecto del surgimiento y la estabilidad de la democracia (movilidad de los factores productivos, modelos de interacción entre dos y tres clases sociales, posibilidades de represión y amenazas de sublevación de distintos grupos). Este trabajo simplemente hace un análisis diferente de un punto de estas teorías, que es el papel de la distribución del ingreso, y el uso del TVM.

5 Ambas variables intervinientes han estado en el centro del análisis estructuralista (O'Donnell 1982), pero no se ha evaluado con tanta asiduidad su influencia conjunta en la estabilidad democrática. Aquí se utiliza el concepto de régimen de acumulación (Boyer 2007), para dar cuenta del efecto estructural conjunto de las dos variables intervinientes sobre la estabilidad democrática. 
La exploración empírica muestra que también es muy importante para la estabilidad democrática, el efecto combinado de una menor polarización y de altas tasas de expansión del producto. A su vez, el PBI per cápita está muy correlacionado con la disminución de la polarización y con la expansión del producto. De ahí, que una de las principales conclusiones de este trabajo sea que los efectos del PBI sobre la democracia posiblemente no son directos, contrariamente a lo que sostiene Przeworski (2005).

\section{ANTECEDENTES DEL DEBATE EN TORNO A LA RELACIÓN ENTRE EL DESARROLLO ECONÓMICO Y LA DEMOCRACIA}

\section{Una correlación en busca de una teoría}

Con toda seguridad, el filósofo escocés David Hume tenía razón al afirmar que las causas de un fenómeno no pueden ser percibidas, y que en cambio sólo estamos en condiciones de percibir correlaciones. En efecto, uno no puede observar y registrar causas valiéndose de sus sentidos. Pero es justamente este problema, lo que vuelve tan necesaria la especulación teórica. Como sólo percibimos correlaciones, necesitamos darle un orden y sentido lógico a estas percepciones.

Tal vez la explicación más bonita de lo que quiero explicitar fue enunciada por Francis Bacon hace mucho tiempo. Él afirmaba: "quienes han manejado la ciencia han sido, o bien hombres de experimento $\mathrm{u}$ hombres de dogmas. Los hombres de experimento parecen hormigas que se limitan a recolectar y utilizar; los raciocinadores parecen arañas que hilan sus telas utilizando su propia sustancia. Mas la abeja toma el camino de en medio: recoge su material de entre las flores del jardín y del campo, pero lo transforma y lo digiere mediante una capacidad propia".

Posiblemente entonces, los mejores resultados para ciencias sociales puedan conseguirse al recorrer el camino de la abeja, la investigación no puede constituirse únicamente de especulaciones teóricas aisladas, ni de meras correlaciones empíricas. Sin embargo -y curiosamente-, en un tiempo en que la misma noción de causalidad se encuentra en crisis en el campo de las ciencias más duras, como las ciencias físicas, las ciencias sociales parecen confiar en que la sofisticación estadística proveerá a nuestras investigaciones con las causas de los fenómenos que queremos explicar.

Este parece ser el caso de la manida correlación entre el desarrollo económico y democracia. En 2009 se han cumplido 50 años de la afirmación de Lipset: "cuanto mejor lo hace un país, más posibilidades de que sea democrático". La frase, que impresiona por su vaguedad, ilustra bien la perspectiva de Lipset: cuanto más rico, cuanto más industrializado, cuanto más urbanizado es un país, será más democrático. Y en realidad, las correlaciones empíricas entre PBI y democracia fueron entonces la sustancia de todo lo que podía afirmarse.

De ahí en más, infinidad de tinta ha corrido en trabajos que evalúan estadísticamente esta correlación, pero mucho menos se ha trabajado para combinar el plano teórico con el empírico. Por eso, el nombre de Teoría de la Modernización implica una contradicción 
en sí misma, pues en realidad esta corriente se sostiene únicamente sobre una correlación, y está desprovista de un sustento teórico capaz de relacionar directamente el desarrollo económico con la democracia.

Esquema I: La teoría de la modernización en la versión de Lipset (1959) según Wucherpfennig y Deutsch (2009)

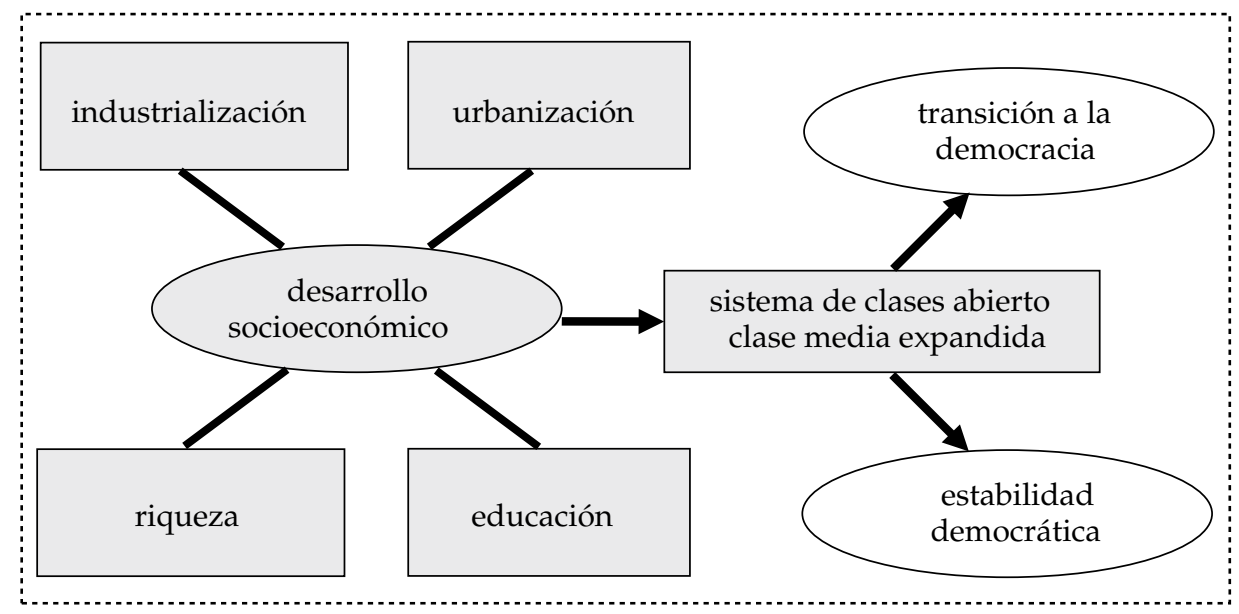

Fuente: Wucherpfennig y Deutsch (2009).

Wucherpfennig y Deutsch (2009) recogen en un esquema (ver Esquema I) la propuesta de la Teoría de la Modernización en su versión de Lipset (1959). Allí puede apreciarse cómo el desarrollo económico no se encuentra directamente ligado con la democracia (como tampoco lo están ninguna de las otras dimensiones del "síndrome de la modernización" propuesto por Lipset: industrialización, urbanización, riqueza, educación). En el esquema se aprecia cómo el desarrollo económico incide sobre la democracia a través de la estructura de clases. La relación no es entonces directa, sino mediada por factores de índole distributiva.

\section{Przeworski y la versión exógena de la modernización}

Luego de realizar un repaso a numerosos artículos y trabajos ampliamente citados, sólo en un caso he encontrado un argumento que intenta ligar directamente el nivel de desarrollo económico de un país y la democracia. La proeza -dicho esto sin la menor ironía- se debe a un trabajo de Adam Przeworski (2005), y el argumento es el siguiente: como es lógico suponer que el ingreso reporta una utilidad marginal decreciente, entonces en los países ricos las personas estarían más dispuestas que en los países pobres a sacrificar algo de su ingreso, si con eso consiguen mantener la democracia.

Esta disposición para el sacrificio de ingresos permitiría solucionar conflictos sociales internos entre ricos y pobres, y eso explicaría la alta estabilidad de la democracia en 
los países desarrollados. El razonamiento es ingenioso, y no tan evidente hasta su formalización explícita por Przeworski. Asimismo, el autor reafirma una distinción lógica entre el problema de la democratización por un lado, y el de la estabilidad democrática por el otro. Esta es una discriminación muy útil en términos teóricos y prácticos, y permite a Przeworski et al. (2001) defender el papel exógeno del desarrollo económico en su incidencia sobre la democracia.

Desde esta perspectiva, el PBI per cápita permite predecir si una democracia durará o no, aunque no es tan eficaz para conocer si se producirá una transición hacia la democracia. En otras palabras, para Przeworski tanto los países ricos como los pobres suelen democratizarse, pero las democracias sólo quiebran en países pobres, por eso los ricos tienden a ser más democráticos.

Pero como se aprecia, ni siquiera estos son argumentos que liguen directamente a la democracia con el desarrollo económico. En definitiva, sólo frente al riesgo de quiebre de la democracia por conflictos distributivos (Prezworski, 2005: 5) la riqueza serviría para ayudar a evitar este quiebre. Pero es evidente, que la explicación radica en que la riqueza brinda condiciones que facilitan el sacrificio del ingreso, y que así es más fácil solucionar los problemas distributivos que amenazan con quebrar la democracia.

Así, aun en el argumento de Przeworski, la influencia del desarrollo económico sólo opera solucionando un problema distributivo, y recién después esto permite explicar la supervivencia de la democracia. Por eso, siguiendo su argumento, si un país tuviera una distribución completamente equitativa del ingreso, ¡tendría entonces una democracia completamente estable! En esta situación resulta completamente indiferente si el país es rico o pobre. Así, el desarrollo económico siempre es un factor subsidiario y secundario, si se lo compara con la importancia de la distribución del ingreso. ${ }^{6}$

Quizás el lector se sienta amenazado por lo rotundo de esta afirmación, pero quiero provocarlo con un argumento: ¿por qué poseer más bienes materiales, dominar mejor nuestro entorno, en fin, ser más desarrollados económicamente, nos volvería más democráticos?

Los antiguos griegos no construyeron una democracia plena y extendida, pero mantuvieron por largos períodos de tiempo una convivencia política de amplia participación, que inspira el nombre de democracia en las modernas poliarquías. ¿Y acaso el desarrollo económico de estos hombres vestidos de toga puede compararse en algo con el nuestro? Parece evidente que la variable desarrollo económico ha operado sobre la democracia intermediada por una tercera variable, y esta tercera variable es la distribución del ingreso.

6 Además, parece que para Przeworski los conflictos distributivos se producen únicamente por el nivel de consumo efectivo: si se alcanza cierto PBI per cápita los hombres comienzan a estar dispuestos a sacrificar ingresos. Esto va en contra de la intuición; siempre creí que los conflictos distributivos se deben a que los hombres comparan sus niveles de riqueza, y ambicionan lo que el otro tiene, sin importar qué tan ricos son. Finalmente, el argumento de Przeworski tampoco toma en cuenta los conflictos en torno a los modos de producción y al disfrute del ocio. Para llegar a un determinado nivel de PBI per cápita, es necesario trabajar bajo un determinado esquema de reparto de tareas, esfuerzo y descanso, y esto genera conflictos, también en los países ricos. 


\title{
Distribución del ingreso y democracia: entre el TVM y la polarización de los más pobres
}

\begin{abstract}
"Y las democracias son más seguras y de más larga duración que las oligarquías a causa de la clase media (cuyos miembros son más numerosos y participan más de los honores políticos en las democracias que en las oligarquías). Mas cuando falta la clase media y los pobres alcanzan un número extremado sobreviene la adversidad y las democracias pronto se arruinan". Aristóteles "La Política", c. 325 A.C.
\end{abstract}

La tradición teórica que liga la distribución del ingreso a la prevalencia de distintas formas de convivencia política, es mucho más venerable y antigua que la Teoría de la Modernización. No es éste el lugar para argumentar las razones por las que podrían ubicarse en esta tradición a Platón, Aristóteles, Tomás Moro, Hobbes, Locke, Rousseau y Marx, entre otros. Modernamente, esta tradición también ha dado lugar a interesantes desarrollos en el campo de la Ciencia Política y la Economía Política.

Algunos de los aportes más recientes sobre el tema provienen de la Economía, y aplican el Teorema del Votante Mediano (TVM) al estudio de tensiones distributivas. Dos de los trabajos más interesantes en torno al problema de los conflictos distributivos y la inestabilidad democrática (Acemoglu y Robinson, 2005: 99-113; y Boix, 2003: 23) han aplicado este razonamiento. La conclusión general simplificada de estos importantes aportes es que cuanto más pobre sea el individuo de la mediana, ${ }^{7}$ mayores impuestos redistributivos estará dispuesto a votar.

De ahí se sigue que, cuanto mayor sean los impuestos aprobados, es de esperar más resistencias por parte de los más ricos, y por lo tanto se elevará el tenor de los conflictos distributivos. En conclusión: las probabilidades de un quiebre de la democracia debido a conflictos distributivos aumentan en aquellos países donde el votante mediano es más pobre.

A pesar de lo interesante de este razonamiento, el TVM supone a nuestro entender notorias limitaciones para evaluar las tensiones distributivas en una sociedad. Bajo ciertas circunstancias, el votante mediano es muy importante para obtener una mayoría en una elección democrática. Pero el teorema da por supuesto que este individuo es la única clave para establecer coaliciones redistributivas.

Este es un supuesto poco probable, porque para redistribuir no basta con el voto de un solo individuo, sino que es necesario construir una coalición entre las personas más pobres. $Y$ en la realidad, la distancia de ingresos entre el votante mediano y el votante más pobre puede resultar muy grande, lo que dificulta su acción colectiva. De modo que, si se contemplara la posibilidad de abstención, o si se pudiese escoger entre más de dos partidos, habría pocas probabilidades de conformar una coalición que articule bajo una misma propuesta redistributiva al votante más pobre y al votante mediano.

$7 \quad$ El votante mediano es aquel que tiene a su derecha a la mitad de la población más pobre y que quiere impuestos más altos, y a su izquierda a la otra mitad rica que quiere impuestos más bajos. Bajo una serie de supuestos articulados en el TVM, esta posición de la mediana tiene la particularidad de ser necesaria para conseguir una mayoría electoral. 
Creo que en lugar de prestar atención sólo al votante mediano, habría que evaluar el grado de polarización de los más pobres. La relación entre una menor polarización económica y la estabilidad política fue establecida por Aristóteles hace más de 2.300 años. En el campo de la Economía, debido a tendencias empíricas recientes, el tema de la polarización en la distribución del ingreso ha merecido renovado interés. Referido a la estabilidad de las democracias contemporáneas el problema está presentado en Traversa (2007) en términos formales y empíricos.

Para evitar desarrollos formales expondremos primero este argumento en forma intuitiva. El interés por redistribuir depende de qué tan pobre sea el 50\% más 1 más pobre de la sociedad. Pero la probabilidad de que esta coalición de pobres se ponga de acuerdo, y vote la misma tasa de redistribución, depende de qué tan homogéneamente pobres sean entre sí.

Es decir que, cuanto más bajos y homogéneos sean los ingresos de los más pobres de una sociedad democrática, es más probable que triunfe en las elecciones un partido que proponga una gran redistribución del ingreso. Esta situación enfrenta con mucha mayor probabilidad a pobres y ricos, en torno a tasas impositivas muy disímiles; aumenta las posibilidades de un conflicto abierto, y vuelve menos probable la supervivencia de la democracia.

Sin embargo Traversa (2007) no ofrece un modelo estructurado en términos similares a los de Boix (2003) y Acemoglu y Robinson (2006), y esto vuelve débil al argumento en su capacidad de dialogar con otras perspectivas sobre el mismo problema. Este trabajo, en cambio, parte de supuestos similares al TVM, que vuelven más comprensible el argumento, y le permite dialogar con más fluidez con diversas perspectivas sobre la estabilidad democrática.

\section{UN MODELO ANALÍTICO PARA COMPRENDER LOS FACTORES QUE FAVORECEN LA ESTABILIDAD DE LA DEMOCRACIA CAPITALISTA}

\section{Desarrollo económico y estabilidad de la democracia: un esquema para comprender la relación entre ambos fenómenos}

Hace ya algunas décadas que distintos autores han remarcado que, si bien el modo capitalista de producción está caracterizado por el desarrollo de algunas tendencias generales, estas no se despliegan en todas partes ni en todo tiempo histórico del mismo modo (Gordon et al., 1994: 11).

La acumulación capitalista, entendida como acumulación de capital y expansión de las relaciones salariales de trabajo (Wright, 1983), puede tomar distintas formas estables. Se reconocen entonces diferencias sustanciales en los patrones de acumulación capitalista, que habilitan al surgimiento de conceptos como el de estructura social de acumulación (Kotz et al., 1994) o el de régimen de acumulación capitalista (Boyer, 1997).

El concepto de régimen de acumulación capitalista, en particular, hace referencia al "conjunto de regularidades que aseguran una progresión general de la acumulación del capital (...) estas regularidades conciernen a: un tipo de organización de la producción y relación de los asalariados con los medios de producción, un horizonte temporal de 
valorización del capital (...), un reparto del valor que permite la reproducción de los distintos grupos o clases" (Boyer, 2007: 63)".

El surgimiento de distintos regímenes de acumulación capitalista se ve fortalecido, desde mi punto de vista, por la estructura del comercio internacional que, como sostienen los especialistas, ha favorecido a la especialización productiva. Surgen así capitalismos diferentes y conectados: el capitalismo central, propio de los países de mayor desarrollo relativo, y el capitalismo periférico característico de sociedades más pobres.

Se intentará ahora sentar un punto de vista sobre la relación entre desarrollo económico capitalista y la estabilidad de la democracia. Desde un punto de vista conceptual general, en el Esquema II se aprecia que la estructura de la economía capitalista (esto es, el grado de desarrollo de sus fuerzas productivas, y las relaciones sociales de producción predominantes) favorece la emergencia y reproducción de un régimen particular de acumulación capitalista.

Por su parte, cada régimen de acumulación capitalista está asociado a la prevalencia de determinados patrones de distribución del ingreso y de expansión de la producción. A su vez, las posibilidades de expansión del producto, y las pautas de distribución del ingreso, son factores económicos que inciden con fuerza en el grado de tensión y conflicto político, y estos conflictos afectan la estabilidad de los regímenes democráticos.

Con mayor grado de concreción, en el Esquema III se aprecia por qué desde esta perspectiva, el PBI per cápita se encuentra correlacionado con la estabilidad de las formas democráticas de gobierno. Los países con mayor PBI per cápita suelen representar ${ }^{8}$ regímenes de acumulación capitalista caracterizados por: a) pautas de distribución del ingreso de menor grado de polarización, y b) una expansión estable del producto, con menos recaídas y crisis.

Estos patrones de distribución del ingreso, y la expansión continuada de la producción moderan las tensiones y conflictos políticos debido a factores económicos. El resultado es la constatación de que en países de mayor PBI per cápita se producen menos golpes de Estado y revoluciones, y así la democracia es más estable.

Pero no hay un efecto directo de la riqueza relativa de un país, sobre la estabilidad de la democracia, y si éste existe, es mínimo. Ser ricos no nos vuelve más democráticos. La relación entre el PBI per cápita -que usualmente es tomado como medida del grado de modernización de una sociedad- y la estabilidad democrática, se encuentra mediada decisivamente por factores distributivos.

En el próximo apartado se desarrolla un modelo teórico que intenta explicar desde un punto de vista lógico cómo la disminución de la polarización y las tasas estables de expansión del producto favorecen a la estabilidad democrática (relaciones C y D de los Esquemas I y II).

8 No en todos los casos, en ocasiones - como en el caso de los países con grandes riquezas petroleras- un alto PBI per cápita no está asociado a la presencia de un régimen de acumulación capitalista de gran avance tecnológico, con patrones estables de crecimiento y una distribución no polarizada del ingreso. 
Esquema II: La estructura económica de una sociedad está correlacionada con la estabilidad democrática por los siguientes mecanismos

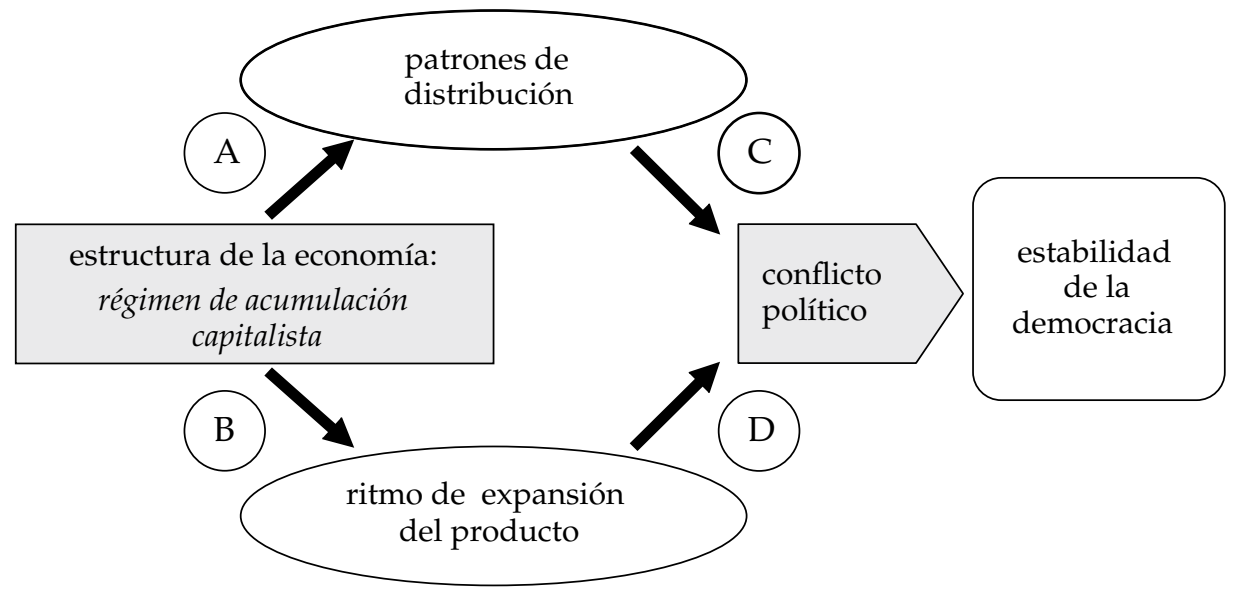

Fuente: Elaboración propia.

Esquema III: El PBI per cápita está correlacionado con la estabilidad democrática por los siguientes mecanismos

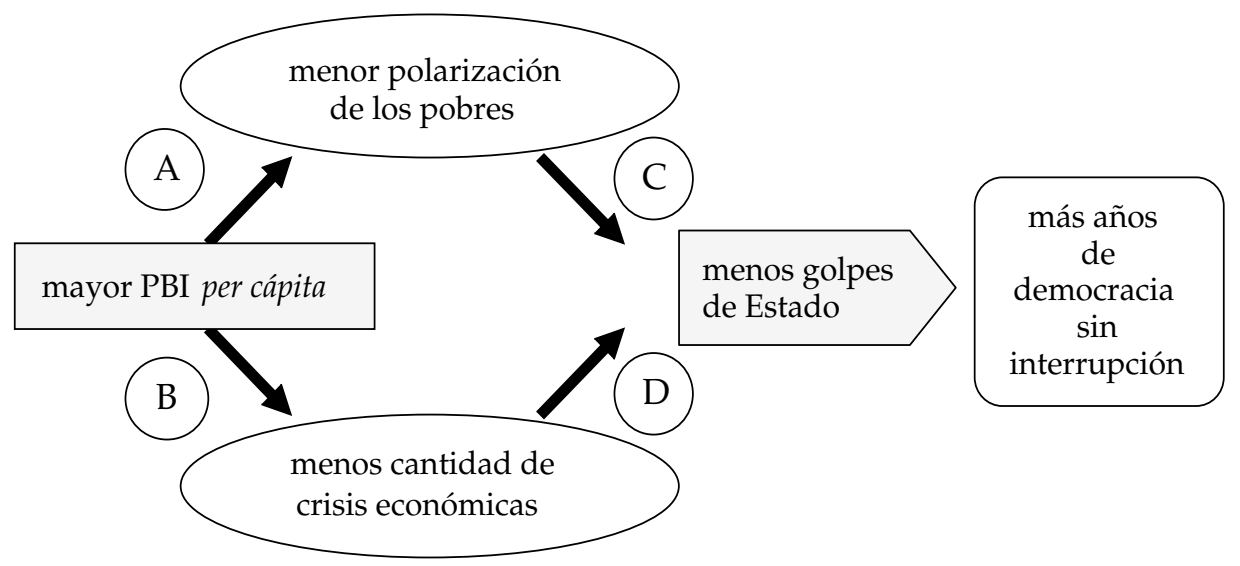

Fuente: Elaboración propia.

\section{Conflicto político en democracias capitalistas: una extensión del TVM contemplando abstención por alienación, y sesgo en la distribución del ingreso}

A continuación se propone un modelo de análisis, que incorpora al TVM dos supuestos razonables y consistentes con la realidad de las democracias capitalistas. El primero, es la existencia de un sector de la ciudadanía que se abstiene de votar por sentirse 
demasiado alejado de las propuestas de los partidos (abstención por alienación). El segundo, es un sesgo en la distribución del ingreso, que la vuelve asimétrica, tal como puede apreciarse en las dos distribuciones de la Figura 1 (este supuesto se aplica a la realidad de todas las economías capitalistas, siempre hay una mayoría de personas con ingresos menores a la media).

Supongamos entonces, una democracia capitalista donde viven dos grupos de ciudadanos. Unos, los pobres, que son una proporción mayoritaria del total, y que tienen ingresos menores a la media. El otro grupo, los ricos, son una proporción minoritaria, y tienen ingresos mayores a la media. Los integrantes de cada grupo no son homogéneos en sus ingresos, de modo que todos los individuos de esta democracia podrían ser ordenados de menor a mayor en función de sus ingresos.

En esta democracia se vota para definir un único asunto, el cobro de una tasa de impuesto $t$ sobre los ingresos de los individuos, esta tasa será mayor o igual a 0 , y menor o igual a 1. El total de lo recaudado se redistribuirá en partes iguales entre todos los ciudadanos, y existe un costo de eficiencia derivado de la aplicación del impuesto.

Así cada ciudadano $(i)$ debe elegir la tasa de impuestos $(t)$ que maximiza su bienestar según la siguiente función:

$$
\max _{t}(1-t) y_{i}+t \bar{y}-\frac{t^{2}}{2}
$$

El primer término recoge la pérdida directa que significa el cobro del impuesto para el individuo, esta pérdida representa una porción $(t)$ de su ingreso $\left(y_{i}\right)$. El segundo término representa la ganancia que significa la redistribución de lo recaudado, cada ciudadano recibirá la enésima parte del total de lo recaudado por impuestos sobre los ingresos de los $n$ individuos; esto es lo mismo que decir que recibirá una proporción $t$ del ingreso promedio $(\bar{y})$.

El último término recoge la pérdida de eficiencia que representa la introducción del impuesto para la economía. Siguiendo a Meltzer y Richards (1981) y tomando la forma específica escogida por Boix (2003), representamos esta pérdida de eficiencia como una magnitud creciente en función de la tasa de impuestos. ${ }^{9}$

De la ecuación se deduce que cada ciudadano tendrá su preferencia respecto a la tasa óptima de impuestos a aplicarse; la tasa que optimiza el bienestar personal ( $\left.t^{*}\right)$ dependerá de los ingresos propios antes de impuestos. Aquellos ciudadanos ricos, con ingresos mayores a la media, preferirán la no aplicación de ningún impuesto, o lo que es lo mismo, su tasa óptima es igual a 0 . En cambio entre los pobres, se preferirá la aplicación de algún impuesto, que será tanto mayor, cuanto mayor sea la distancia entre los ingresos del individuo pobre en cuestión $\left(y_{i}\right)$, y la media de ingresos del país $(\bar{y}) \cdot{ }^{10}$

9 Para que la magnitud de las pérdidas asociadas al impuesto resulten plausibles, estamos asumiendo también como Boix (2003: 23) que el ingreso medio en la economía es igual a 1.

10 Cuanto mayor sea esta diferencia, mayor será la diferencia entre lo percibido por la redistribución (t. $\bar{y}$ ), y lo que el individuo debe pagar por concepto de impuestos (t. $\left.y_{i}\right)$. 
Supongamos ahora que en esta democracia compiten distintos partidos políticos, proponiendo cada cual una tasa de impuesto a ser aplicada. Los partidos conocen aproximadamente cuál es la distribución de ingresos entre los ciudadanos, y por lo tanto pueden estimar con cierta precisión sus tasas impositivas óptimas.

Los ciudadanos, por su parte, votan por aquel partido cuya propuesta impositiva se acerca más a su tasa óptima $t^{*}$. Todos los ciudadanos tienen derecho al voto, pero algunos se abstienen si consideran que las propuestas impositivas de los partidos se encuentran muy alejadas de sus preferencias, supuesto denominado abstención por alienación (Hinich y Munger, 1997). Damos por supuesto que un ciudadano cualquiera se abstendrá de votar, si ninguna de las propuestas de los partidos está a una distancia menor o igual a una magnitud $n$, respecto de su tasa óptima $\left(t^{*}\right)$.

Luego de las elecciones, se aplicará la tasa impositiva propuesta por el partido que obtiene más votos. Tanto los ricos como los pobres valoran vivir en democracia, pero aquellos ciudadanos que encuentran que la tasa impositiva aplicada difiere demasiado respecto de su tasa óptima, conspiran en contra de la democracia. Si el número de estos individuos es suficientemente alto, se produce un intento concreto de desestabilización (golpe de Estado), de los cuales, una proporción arbitraria $(\delta)$ resultan exitosos.

De los supuestos explicitados se deriva la siguiente dinámica política. Llegado el momento de la elección, los partidos eligen su tasa impositiva, para que la ciudadanía los vote. Según la versión original del TVM la respuesta óptima de ambos partidos es competir por el voto del votante mediano, sin embargo con el agregado de los supuestos de abstención por alienación y distribución asimétrica del electorado, ocurre algo distinto. Ahora, los partidos buscan minimizar las pérdidas de electorado debido a la abstención por alienación.

La Figura 1 representa dos distribuciones del electorado. Ambas cumplen con las características típicas de la distribución del ingreso en economías capitalistas, la distribución de la población es asimétrica con un solo pico o moda $(\mathrm{m})$, que en cada caso está ubicado en lugares diferentes. Pero en ambas distribuciones, el punto que asegura a los partidos las menores pérdidas de votantes por alienación, es justamente la moda de la distribución; desde esa posición, donde la distribución del electorado es más densa, es posible maximizar los votos como se aprecia en las áreas grises de la Figura 1.

Un partido que logre ubicarse en la moda será entonces el más votado. ${ }^{11}$ El nuevo equilibrio está ahora allí: los partidos tienden a competir proponiendo una tasa impositiva

11 Pueden existir otros partidos, ubicados en otro sitio de la distribución. Basta que tenga algún incentivo para presentarse a la elección. El resultado general del modelo parece bastante razonable: pueden existir varios partidos, pero el más votado se ubicará en la moda. También puede existir una proporción de ciudadanos que decida no votar por ningún partido. Para concluir que triunfa un partido ubicado en la moda, hemos realizado, además, otra simplificación: no tomamos en cuenta que los más ricos no tienen problemas de acción colectiva, en tanto todos aquellos con ingresos mayores a la media coinciden en que quieren una tasa de impuestos igual a 0 . No consideramos este punto ya que, igualmente, la tasa impositiva más alta se aprobará cuando los pobres están muy polarizados, y siempre es la tasa impositiva más alta la que lleva a los golpes de Estado según Boix (2003) y Acemoglu y Robinson (2006). 
cercana a la que desean aquellos individuos con ingresos más corrientes o usuales. De aquí se deriva el punto más relevante de nuestro argumento. Cuanto más similares sean los ingresos de los más pobres entre sí, y cuanto más pobres sean, existen mayores probabilidades para que el partido más votado se encuentre muy a la izquierda de la distribución, y proponga tasas redistributivas muy altas (segunda distribución de la Figura 1).

Figura 1: Competencia electoral con abstención por alienación y distribución asimétrica del ingreso: tasas impositivas triunfadoras en el capitalismo central y el periférico.
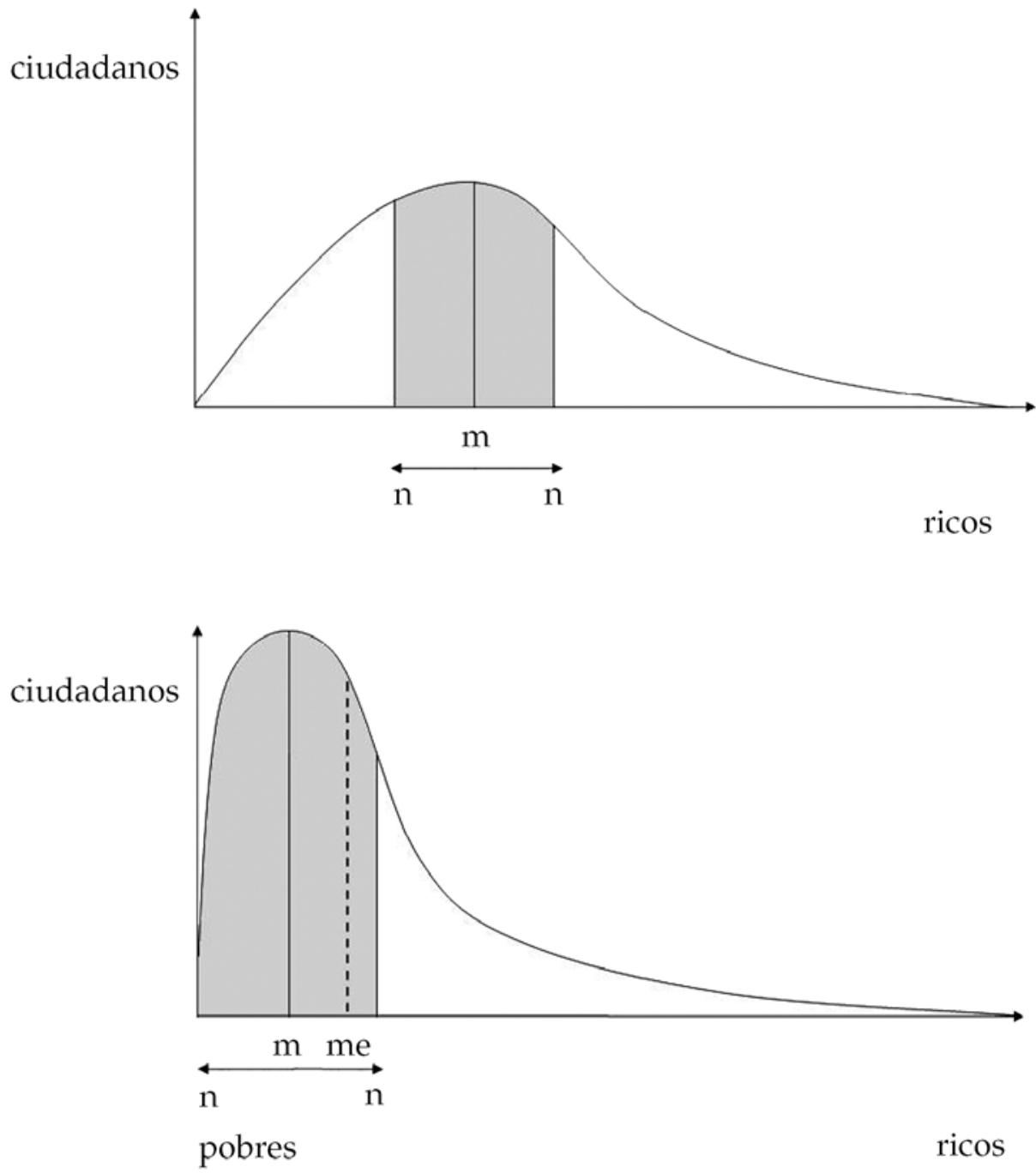

Fuente: Elaboración propia. 
Si los pobres son muy pobres y homogéneamente pobres, la parte izquierda de la distribución de frecuencias se vuelve muy empinada y poblada. De este modo, los partidos buscan con más decisión al electorado más pobre, pues pierden más si no lo hacen, y además arriesgan poco al moverse en esta dirección, pues saben con cierta exactitud que esta parte de la distribución frecuencias del electorado es muy abigarrada. En otras palabras, los partidos se moverán en dirección a proponer una tasa más alta, cuanto más "homogéneamente" pobres sean los más pobres, cuanto más polarizados se encuentren (Traversa, 2007).

En la Figura 1 pueden apreciarse dos distribuciones de los ciudadanos. Como podrá comprobarse en la próxima sección, la primera simula los patrones de distribución del ingreso propios de los regímenes de acumulación capitalista de los países centrales. Encontramos allí una distribución asimétrica del ingreso, sin embargo la mediana y la moda de la distribución están ubicadas más o menos en la misma posición. La población se encuentra distribuida de forma relativamente homogénea, con sectores de ingresos medios de relativa importancia.

La segunda distribución simula los patrones de distribución del ingreso propios de los países del capitalismo periférico. Nuevamente encontramos una distribución del ingreso asimétrica, pero ahora los pobres se encuentran muy polarizados y los sectores medios están muy reducidos. La moda de la distribución está muy cercana a los individuos más pobres de la sociedad, por lo tanto los partidos competirán por acercarse a una posición que implica la aplicación de una tasa impositiva muy alta, más alta incluso que la posición de la mediana, que se encuentra marcada con líneas punteadas.

En la primera situación, las probabilidades de un golpe de Estado no son muy altas, pues no existe una porción importante del electorado que se encuentre demasiado alejada de la tasa impositiva a adoptarse (m). En el segundo caso, en cambio, las probabilidades de quiebre de la democracia son mucho más altas, ya que una porción importante del electorado se encuentra muy alejada de la tasa aplicada (m). Los más ricos, en particular, se volverán muy desleales respecto al resultado del juego democrático en estas condiciones.

\section{El papel de la expansión sostenida del producto en la reducción de las tensiones políticas}

Finalmente, resta agregar un último supuesto a nuestro modelo, de modo de dar cuenta del papel de la expansión del producto en la atenuación de los conflictos políticos. El argumento es muy sencillo: si siguiendo a Meltzer y Richards (1981) aceptamos que la introducción de un impuesto afecta la eficiencia de la economía, creando distorsiones en la inversión y el trabajo, entonces estos riesgos no deberían ser evaluados por los ciudadanos con independencia de los resultados recientes de la economía.

En efecto, si la economía ha estado creciendo, los ciudadanos deberían ser más cautos respecto a las distorsiones que puede crear un impuesto. Suponemos aquí, que el mejor estimador del ingreso futuro de un ciudadano es su ingreso actual, más la tasa de crecimiento que tuvo el producto en el último período. Así, si la economía ha estado creciendo, esto es síntoma de la importancia de la inversión, y los ciudadanos evaluarán como más inconveniente el colocar una tasa de impuestos alta. Por otra parte, si la economía ha estado en recesión, 
los riesgos de una mayor redistribución inmediata del producto pueden ser desestimados. Puesto que la inversión no ha estado dando réditos concretos a los ciudadanos, la retórica de los costos asociados a la redistribución pierde fuerza.

$$
\max _{t}(1-t) y_{i}+t \bar{y}-\frac{\left(t+\Delta \bar{y}_{t-1}\right)^{2}}{2}
$$

Este argumento ha sido incluido en la ecuación (2), donde al último término que incluye los costos por pérdida de eficiencia del impuesto, se le ha agregado un nuevo componente, la tasa de crecimiento del ingreso medio en el último período. Si la economía ha estado en recesión, los ciudadanos desdeñarán los costos por pérdida de eficiencia asociados a un aumento inmediato de la redistribución. En cambio, si la economía ha crecido, los ciudadanos serán más cautelosos, y preferirán reducir la tasa óptima de impuestos a aplicar.

\section{Conclusiones generales del modelo}

Del modelo propuesto extraemos dos conclusiones: a) cuanto más lejanos a la media de ingresos estén los pobres, y cuanto más homogéneos sean sus ingresos, más marcada y menor será la moda, y mayor tasa de redistribución propondrá el partido más votado, b) los ciudadanos de la moda estarán dispuestos a aceptar tasas de redistribución mayores, cuanto menor haya sido la tasa de crecimiento del ingreso en el último período. Estos dos factores favorecen grandes redistribuciones, y aumentan las probabilidades de un golpe de Estado por parte de los ricos.

\section{EXPLORACIÓN EMPÍRICA SOBRE ALGUNOS CONDICIONANTES ECONÓMICOS DE LA ESTABILIDAD DEMOCRÁTICA}

En esta sección se explora la plausibilidad empírica de las conclusiones extraídas a partir del desarrollo teórico. Los datos utilizados provienen de cuatro fuentes: la clasificación de regímenes de gobierno utilizada es la construida por Przeworski et al. (2001); los datos sobre PBI per cápita y su evolución temporal provienen de los trabajos del reconocido historiador económico Angus Maddison (2003); los datos sobre distribución del ingreso de la base de datos más amplia y actualizada sobre el tema (ONU-Wider, 2008), finalmente se utilizaron algunos datos sobre educación provenientes del Banco Mundial. En el Esquema IV se reseñan las principales variables que serán mencionadas a lo largo de la sección, especificando su significado y fuente, con la finalidad de facilitar la lectura posterior de los cuadros.

Cada régimen democrático clasificado como tal por Przeworski et al. (2001) durante el período 1945-2001, representa un caso. A veces un país puede estar representado por más de un caso, en tanto haya tenido dos o más períodos democráticos interrumpidos por dictaduras entre 1945 y 2001. Todas las variables fueron calculadas en función de cada caso: por ejemplo, la variable Democracia_sum se calculó como la duración en años de cada caso, la variable Madison representa el valor medio de la renta per cápita en cada caso, y lo mismo sucede con todas las variables restantes (ver Esquema IV). 
La única variable que merece una explicación particular es el Índice de Estabilidad Distributiva (IED), que fue calculado especialmente para este trabajo. El índice representa un inverso de la polarización de ingresos de los sectores más pobres, es decir, que arroja valores más altos, cuanto más altos y más diferentes entre sí son los ingresos de los más pobres. El IED se calculó como la suma de dos componentes: 1) los ingresos del 60\% más pobre de la población y 2) la dispersión de ingresos entre este mismo grupo del $60 \%$ más pobre de la población (dispersión medida a partir del cuadrado de la distancia entre el tercer quintil y el primer quintil).

Esquema IV: Principales variables consideradas

\begin{tabular}{|c|c|c|}
\hline Variable & Descripción & Fuente \\
\hline Democracia_sum & $\begin{array}{l}\text { Estabilidad democrática: años de duración de } \\
\text { un régimen democrático sin interrupciones } \\
\text { durante el período 1945-2002 }\end{array}$ & $\begin{array}{l}\text { Base de datos usada por } \\
\text { Przeworski et al. (2001) }\end{array}$ \\
\hline MADISON & $\begin{array}{l}\text { Desarrollo económico: valor promedio del } \\
\text { PBI per cápita (en dólares internacionales } \\
\text { Geary-Khamis 1990) mientras dura un } \\
\text { régimen democrático }\end{array}$ & $\begin{array}{l}\text { Base de datos de } \\
\text { Maddison } 2003\end{array}$ \\
\hline Gini_media & $\begin{array}{l}\text { Desigualdad: valor promedio reportado de } \\
\text { Índice de Gini mientras dura un régimen } \\
\text { democrático }\end{array}$ & (ONU-Wider, 2008) \\
\hline Ingresospobres & $\begin{array}{l}\text { Suma de los ingresos reportados del } 60 \% \text { más } \\
\text { pobre respecto del total }\end{array}$ & $\begin{array}{l}\text { Elaboración propia en } \\
\text { base a (ONU-Wider, } \\
\text { 2008) }\end{array}$ \\
\hline DispersiónPobres & $\begin{array}{l}\text { Cuadrado de la diferencia de ingresos entre } \\
\text { valores reportados de quintil } 3 \text { y quintil } 1\end{array}$ & $\begin{array}{l}\text { Elaboración propia en } \\
\text { base a (ONU-Wider, } \\
\text { 2008) }\end{array}$ \\
\hline IED & $\begin{array}{l}\text { Índice de Estabilidad Distributiva: es una } \\
\text { medida inversa a la polarización, igual a } \\
\text { Ingresos pobres + Dispersión pobres }\end{array}$ & $\begin{array}{l}\text { Elaboración propia en } \\
\text { base a (ONU-Wider, } \\
\text { 2008) }\end{array}$ \\
\hline Educ_ & $\begin{array}{l}\text { Educación: promedio matriculación bruta en } \\
\text { enseñanza primaria }\end{array}$ & (Banco Mundial, 2005) \\
\hline
\end{tabular}

\section{¿Existen regímenes de acumulación? La relación del PBI per cápita con la distribución del ingreso y los ritmos de expansión del producto}

En la sección I afirmamos que la literatura en general no maneja argumentos lógicos que liguen el desarrollo económico directamente con la estabilidad democrática (salvo, y con reparos, el mencionado trabajo de Przeworski de 2005). No es de descartar entonces que la manida relación entre ambas variables pudiera estar intermediada con gran fuerza por otras variables intervinientes; aquí se han propuesto dos: una disminución en la polarización de ingresos de los sectores más pobres y tasas estables de expansión del producto. 
El concepto de régimen de acumulación permite articular estos conceptos. En países de alto PBI per cápita existen mayores posibilidades para desarrollar estrategias de acumulación intensivas (Boyer, 2007) y autocentradas (Amin, 1976). Respecto al primer punto, en los países ricos o centrales, el régimen de acumulación capitalista suele apoyarse en continuas ganancias de productividad, que aseguran tasas más estables de expansión del producto.

A su vez, las ganancias de productividad generan condiciones propicias para el surgimiento de distintos sectores de asalariados, que tienen ingresos más o menos proporcionales a la evolución de la productividad en su rama de producción específica. Esto favorece un reparto del ingreso más diverso y menos polarizado al interior de los sectores más pobres. Por su parte, la existencia de mayores ingresos entre los sectores más pobres favorece "el cierre autocentrado" del ciclo de acumulación, a través de la expansión del consumo local.

Lo contrario sucedería en países de menor PBI per cápita, donde la estrategia de acumulación es extensiva y extravertida. El grueso de la producción se ubica en sectores de baja productividad y dinamismo, direccionados a mercados externos. Las bajas tasas de inversión y la dependencia de mercados y precios internacionales provocan tasas más inestables de expansión del producto; mientras que el grueso de la mano de obra asalariada se ubica en sectores de baja productividad, lo que favorece la prevalencia de pautas de distribución del ingreso polarizadas.

Ahora nos proponemos evaluar si la existencia de estos dos "tipos ideales" de regímenes de acumulación es una hipótesis plausible. En primer lugar, efectuamos una correlación simple entre el PBI per cápita por un lado, y las tasas de expansión del producto y dos medidas de distribución del ingreso por el otro. Si no existe una correlación significativa en términos estadísticos, sería necesario abandonar desde ya la hipótesis propuesta.

Tabla 1: Correlación simple entre el PBI per cápita y algunas variables seleccionadas

\begin{tabular}{lcccc}
\hline & EDUC & IED & Gini & crecmadd_pgt \\
\hline Correlación Pearson &, $222\left(^{*}\right)$ &, $675\left(^{* *}\right)$ &,$- 510\left(^{* *}\right)$ &, $\left.345^{* *}\right)$ \\
Sig. (bilateral) &, 038 &, 000 &, 000 &, 000 \\
Casos & 88 & 64 & 98 & 141 \\
\hline
\end{tabular}

* La correlación es significante al nivel 0,05 (bilateral).

** La correlación es significativa al nivel 0,01 (bilateral).

Como preveíamos, el resultado es que el PBI per cápita sí se encuentra correlacionado positivamente con tasas estables de expansión del producto. También se encuentra correlacionado con pautas especiales de distribución del ingreso: los países más ricos tienen menores niveles de desigualdad medida a través del Índice de Gini, pero incluso es más fuerte la relación entre la riqueza relativa y la disminución de la polarización medida a través del IED ${ }^{12}$ (Tabla 1). Asimismo, el PBI per cápita se encuentra correlacionado

12 En el Cuadro II puede apreciarse como el Índice de Gini -medida de desigualdad usualmente utilizada para evaluar la incidencia de la distribución del ingreso en la estabilidad democrática-no muestra una correlación tan fuerte respecto al desarrollo económico medido a partir del PBI per cápita. Es conocido que el comportamiento del 
significativamente con otra variable que será objeto de análisis posteriormente: la tasa bruta de matriculación en enseñanza primaria.

A continuación, seguimos la exploración a través de un análisis de clusters o conglomerados. Este análisis, como el anterior, tiene la finalidad únicamente descriptiva de clasificar a 65 regímenes democráticos de distintas partes del mundo en el período 1946-2001,13 en función de sus tasas promedio de PBI per cápita, IED y expansión del producto.

Luego de cuatro iteraciones fue posible agrupar dos conglomerados de K medias, integrados por 40 casos y 25 casos cada uno. Como resultado, uno de los conglomerados agrupó democracias que en promedio tienen alto PBI per cápita $(10784,20)$; alto IED y por lo tanto baja polarización $(156,21)$, y tasas más estables de expansión del producto $(81,8 \%$ de los años de crecimiento por encima de 0 ). Los otros 40 casos de regímenes democráticos integran un conglomerado de menor PBI, menor IED, y menor porcentaje de años de expansión del producto (Tabla 2).

Tabla 2: Análisis de conglomerados en 65 regímenes democráticos: PBI, IED y expansión del producto

\begin{tabular}{lcc}
\hline \multirow{2}{*}{ Variables } & \multicolumn{2}{c}{ Centros de los conglomerados finales } \\
\cline { 2 - 3 } & $\begin{array}{c}\text { Conglomerado 1 } \\
\text { (democracias periféricas) }\end{array}$ & $\begin{array}{c}\text { Conglomerado 2 } \\
\text { (democracias centrales) }\end{array}$ \\
\hline MADISON & 3.165 & 10.784 \\
IED & 95,4 & 156,2 \\
Años_expansión & $73 \%$ & $82 \%$ \\
\hline Total de casos & 40 & 25 \\
\hline & & \\
\hline \multicolumn{1}{c}{ Iteración } & Historial de iteraciones (a) & 6070,316 \\
\hline 1 & Cambio en los centros de los conglomerados \\
\hline 2 & 3214,612 & 664,447 \\
4 & 555,782 & 128,834 \\
& 110,440 &, 000 \\
\hline
\end{tabular}

(a) Se ha logrado la convergencia debido a que los centros de los conglomerados no presentan ningún cambio o éste es pequeño.

Gini conforme crece el PBI no muestra una relación monotónica, sino que más bien conforma una U invertida, patrón recogido por la conocida "curva de Kusnetz". El signo de la relación es el esperado, a más PBI per cápita, menor valor de Gini -y por lo tanto menos desigualdad-. La media de ingresos del primer quintil, por su parte, tampoco muestra una alta correlación con el PBI per cápita, aunque el signo de la relación es el esperado previamente, a más PBI per cápita, mejora la participación del 20\% más pobre en los ingresos totales.

13 Podríamos haber evaluado países en lugar de regímenes democráticos, pero como el trabajo se concentra en la estabilidad democrática como problema, se optó por estudiar entonces regímenes como unidad de análisis. Se incluyeron en el análisis los 65 regímenes democráticos del período 1945-2001, para los que se contó con datos de PBI, IED y expansión del producto. 
Estas exploraciones muestran la potencialidad del concepto de régimen de acumulación. Parece existir dos grupos de democracias bien diferenciados, las del capitalismo central con alto PBI, baja polarización y crecimiento estable, y las del periférico, de características completamente opuestas.

\section{Estabilidad democrática y regímenes de acumulación}

A continuación se evaluará más directamente la influencia de algunas variables económicas sobre la estabilidad democrática. Se analizaron todos los regímenes democráticos del período 1945-2001, para los que se contaba con datos de PBI per cápita, IED y expansión del producto. ${ }^{14}$ Recordemos que cada caso está constituido por un régimen democrático que se inicia dentro del período 1945-2001, y que puede finalizar en cualquier momento debido a un golpe de Estado (sucede en 11 casos) o sobrevivir hasta el final del período de estudio en el año 2001.

En primera instancia, y con una finalidad puramente descriptiva, se procedió a evaluar la duración media de los regímenes democráticos agrupados según los conglomerados construidos en la sección anterior. El resultado es que en el grupo del capitalismo central, la duración media de los regímenes democráticos es de 47 años (Grupo 2).

Tabla 3: Duración media de la democracia en los conglomerados

\begin{tabular}{ccccc}
\hline & & \multicolumn{2}{c}{$\begin{array}{c}\text { Intervalo de confianza para la } \\
\text { media al 95\% }\end{array}$} & Total de casos \\
\cline { 3 - 4 } Conglomerado & Media & $\begin{array}{c}\text { Límite } \\
\text { inferior }\end{array}$ & $\begin{array}{c}\text { Límite } \\
\text { superior }\end{array}$ & \\
\hline $\begin{array}{c}1 \\
\text { Democracias periféricas } \\
2\end{array}$ & 18,4 & 14,4 & 22,5 & 40 \\
$\begin{array}{c}\text { Democracias Centrales } \\
\text { Todas las democracias }\end{array}$ & 47,1 & 40,1 & 54,1 & 25 \\
\hline
\end{tabular}

Mientras tanto, en el conglomerado de democracias periféricas, la media de duración del régimen es de 18 años (Grupo 1). Asimismo, en el grupo de alto desarrollo y baja polarización, ninguno de los regímenes se vio interrumpido por un golpe de Estado.

14 Para la inmensa mayoría de estos períodos se contaba con mediciones de PBI per cápita obtenidas de la base de MADISON, no ocurre lo mismo respecto a las mediciones de distribución del ingreso, que son mucho menos comunes en el período previo a 1960, y respecto de las cuales en ocasiones no se encuentran datos de distribución del ingreso por deciles y quintiles, valores necesarios para construir nuestro IED. Sin embargo, usando todos los datos de distribución del ingreso disponibles, sin dejar casos fuera de consideración, pudo calcularse el IED para 64 períodos democráticos entre los años 1946-2002, para los que también podían encontrarse datos de PBI per cápita (MADISON). De la muestra anterior, de 65 países se eliminó Alemania Occidental en tanto que luego de la reunificación podría considerarse que el país que finaliza el período de estudio en 2002 no es estrictamente el mismo que lo inició, de todos modos su inclusión no cambiaría los resultados aquí presentados. 
Mientras que los 11 regímenes que finalizaron con un golpe de Estado se encuentran en el capitalismo periférico.

Posteriormente, se exploraron los efectos de distintas variables socioeconómicas, sobre la duración de los regímenes democráticos (Democracia_sum), a partir de cinco regresiones lineales múltiples. En el primer modelo resumido en la Tabla 4, se exploran los efectos del PBI per cápita y de la expansión estable del producto. Ambas variables muestran coeficientes significativos, y la relación es la esperada: mayor PBI per cápita y mayor porcentaje de años de expansión del producto están asociados con una mayor duración de los regímenes democráticos.

En el segundo modelo se agrega el Índice de Gini. El resultado es que sólo el PBI per cápita muestra ahora un coeficiente significativo, el coeficiente calculado para el Índice de Gini no es significativo. En el tercer modelo se introduce el IED y se retira el Índice de Gini. El modelo se ajusta ahora un poco mejor, y en este caso el IED es la variable con el coeficiente de mayor significación estadística. El PBI per cápita continúa siendo significativo, aunque en menor grado que la polarización de ingresos medida a partir del IED.

Tabla 4: Impacto de algunas variables socioeconómicas en la duración de los regímenes democráticos

\begin{tabular}{cccccc}
\hline Variables independientes & $\begin{array}{c}\text { Modelo } \\
(1)\end{array}$ & $\begin{array}{c}\text { Modelo } \\
(2)\end{array}$ & $\begin{array}{c}\text { Modelo } \\
(3)\end{array}$ & $\begin{array}{c}\text { Modelo } \\
(4)\end{array}$ & $\begin{array}{c}\text { Modelo } \\
(5)\end{array}$ \\
\hline MADISON &, $589^{* *}$ &, $616^{* *}$ &, $248^{*}$ & & \\
IED & $(5,334)$ & $(5,219)$ & $(2,074)$ & &, 552, \\
& & &, $845^{* *}$ & & $(1,983)$ \\
Expansión_producto &, $330^{*}$ &, 181 &,- 169 &, $659^{*}$ &,- 300 \\
GINI & $(2,991)$ & $(, 715)$ & $(-1,191)$ & $(3,090)$ & $(-1,944)$ \\
Educa & &, 134 & & & \\
Inter_IED_exp & & $(, 659)$ & & & \\
& & & &, 161 & \\
R cuadrado(a) &, 787 &, 788 &, 844 &, 664 &, 845 \\
R cuadrado corregida &, 780 &, 778 &, 837 &, 656 &, 837 \\
N & 64 & 64 & 64 & 88 & 64 \\
\hline
\end{tabular}

Notas: Regresión a través del origen (modelo sin término de intersección). Se opta por regresiones a través del origen en tanto a priori la variable respuesta no presenta valores negativos, y no se espera que arroje valores mayores a 0 para valores iguales a 0 en las variables regresoras; si se incluye un término constante este no resulta además estadísticamente significativo Coeficientes estandarizados de cada variable, y valores absolutos de estadístico $(t)$ entre paréntesis. * Significativa al 5\%; ** Significativa al $1 \%$. 
A pesar de los altos coeficientes calculados para el tercer modelo, el análisis no permite extraer conclusiones tajantes sobre el modo en que se combinan las distintas variables para afectar la duración de los regímenes democráticos. Como sabemos, IED y PBI son dos variables muy correlacionadas, y pesar que los estadísticos de colinealidad arrojan niveles aceptables, sabemos que una pequeña variación de los datos podría llevar a cambios importantes en los coeficientes estandarizados calculados para cada variable.

En el modelo 4, se intenta una vía alternativa para discriminar cuánto de la influencia del PBI per cápita sobre la estabilidad democrática podría no deberse a los mecanismos causales que aquí he propuesto. Con este propósito se sustituyó el PBI per cápita por la variable Educa, sobre la que contamos con información para 88 regímenes democráticos. Esta variable tiene la particularidad de representar una de las dimensiones que afectarían positivamente a la democracia según Lipset (1959). Pero además -y sobre todo- está correlacionada significativamente con el PBI per cápita (Tabla 1), y no con el IED o la expansión estable del producto.

En el modelo 4, se calculó entonces el efecto de la variable instrumento educación, y de la expansión estable del producto (no se incluyó IED porque son pocos los casos que tienen valores válidos para las tres variables). El resultado es que sólo la expansión estable del producto muestra coeficientes significativos, mientras que no ocurre lo mismo para la variable educación.

Finalmente, el modelo 5 intenta captar el efecto combinado de la expansión del producto y el IED, a través de una variable de interacción (Inter_IED_exp), calculada como el producto de las dos anteriores. Como resultado esta variable recoge coeficientes significativos, y el $r$ ajustado global es el más alto, junto con el que se calculó en el modelo 3. La combinación de la expansión del producto y la reducción de la polarización muestra entonces efectos positivos y significativos sobre la duración de la democracia.

¿Qué conclusiones es posible extraer de la exploración empírica? Es necesario ser muy cautelosos, porque la formulación teórica propuesta supone en sí misma dos dificultades desde el punto de vista estadístico. En primer lugar tenemos los obstáculos que supone la alta correlación entre el PBI y el IED, que dificulta evaluar el efecto preciso de cada una de estas variables respecto a la estabilidad democrática.

En tal sentido, cabe destacar que desde un punto de vista teórico, el modelo propuesto se basa justamente en la alta correlación entre el PBI per capíta y el IED, por lo que la alta correlación entre ambas es una especie de ratificación del modelo. Por otra parte, no se encontró una asociación estadística significativa entre la educación y la duración de la democracia, lo que parece sustentar la hipótesis que aquí defendemos, respecto a los mecanismos causales a través de los cuales opera el PBI sobre la democracia. ${ }^{15}$

15 Sin embargo, es apresurado sacar conclusiones en tal sentido; a pesar que la educación está significativamente asociada al PBI y no lo está al IED, sería deseable que la relación entre las dos primeras variables fuera todavía más alta para confiar aún más en la eficacia de esta variable instrumental. 
Otra dificultad tiene que ver con los efectos cruzados entre la variable dependiente y las independientes, ${ }^{16}$ en tanto que la duración de la democracia podría tener efectos sobre nivel de PBI per cápita y sobre el IED. A este respecto nuevamente vale señalar que, del modelo teórico desarrollado, más que una influencia unidireccional de la IED hacia la estabilidad democrática, en rigor cabría esperar una asociación estadística entre ambos fenómenos. ${ }^{17}$

Estos problemas desde un punto de vista estadístico y teórico parecen prácticamente insolubles (véase al respecto la opinión de Przeworski, 2004). Merecen por lo menos un análisis específico, y no se abordan por tanto en este trabajo. El principal objetivo fue intentar aportar una perspectiva teórico-lógica diferente, y evaluar empíricamente si debe ser descartada de plano, o merece ser objeto de mayor profundización. ${ }^{18}$ A pesar de las limitaciones reseñadas, es posible extraer entonces algunas conclusiones que se exponen en la próxima sección.

\section{CONCLUSIONES}

La expansión del capitalismo vinculó a un mismo mercado economías que, además de presentar grados diversos de diferenciación del sistema productivo, pasaron a ocupar posiciones distintas en la estructura global del sistema capitalista (Cardoso y Faletto, 1969: 23).

Este trabajo vuelve a tratar una pregunta recurrente para la Ciencia Política: ¿cuáles son los mecanismos causales que están detrás de la asociación estadística entre el PBI per cápita y la estabilidad democrática? Aquí se defendió la hipótesis de que no existe una relación directa entre ambos fenómenos. La relación entre ellos se explicaría por la mediación de otras variables, que son los verdaderos mecanismos causales que explican la correlación entre riqueza y estabilidad democrática.

Se arribó a esta hipótesis sobre el problema, a partir de la elaboración de un modelo de competencia electoral que integra dos supuestos compatibles con la realidad de las

16 Los problemas de endogeneidad suelen estar presentes en gran parte de los modelos estadísticos que intentan lidiar con el problema de la estabilidad democrática y no son de fácil solución. En tal sentido, en la medida que la duración de la democracia en teoría puede afectar tanto al PBI como al IED, esto no representaría un problema tan crítico en nuestro caso, pues no nos interesa asignar causalidades unidireccionales, sino simplemente analizar si el PBI podría operar sobre la democracia a través del IED.

17 En efecto, al no quebrarse la democracia gracias a la baja polarización, podrían producirse entonces redistribuciones moderadas sucesivas, que tengan un efecto de retroalimentación al hacer caer aún más la polarización.

18 Los cientistas sociales somos algo proclives a considerar que las técnicas estadísticas más sofisticadas brindan la posibilidad de realizar afirmaciones sobre causalidad a partir de la inferencia estadística. A este respecto vale recordar la afirmación de los estadísticos Kendall y Stuart (1961: 279) "una relación estadística, sin importar qué tan fuerte y sugestiva sea, nunca podrá establecer una relación causal: nuestras ideas de causalidad deben venir, (...) en último término de una u otra teoría". No podemos olvidar que toda técnica estadística se basa en última instancia en la utilización de datos que dan cuenta de meras asociaciones, porque como señalaba Hume sólo podemos percibir -y por lo tanto procesar estadísticamente- asociaciones. Finalmente, vale la pena destacar que la noción misma de causalidad es objeto de fuertes controversias en el marco de las ciencias físicas, debate al cual las ciencias sociales nunca ingresaron, como reconocía hace muchos años García Ferrando (1985). 
democracias contemporáneas, abstención por alienación y distribución asimétrica del ingreso. Como resultado de este análisis teórico, se concluyó que dos variables podían ser los mecanismos causales que explican la estabilidad democrática: una disminución en la polarización de ingresos de los sectores más pobres, y tasas estables de expansión del producto.

Por su parte, la exploración empírica demostró que mayores niveles de PBI per cápita están muy asociados a estas dos variables explicativas. Por lo tanto, no es de descartar que no exista una relación directa entre el PBI y la estabilidad democrática. La relación entre ambas se explicaría porque las democracias más ricas muestran también una menor polarización de ingresos en los sectores pobres, y mayor estabilidad en sus tasas de expansión del producto.

Posteriormente, se efectuó una serie de regresiones lineales para evaluar qué factores estarían incidiendo en la duración de los regímenes democráticos. Los resultados son compatibles con la hipótesis de que la influencia del PBI per cápita sobre la democracia puede procesarse a través de los mecanismos causales propuestos aquí (al que incluso podrían agregarse otras variables para su consideración). ${ }^{19}$

Entre estos mecanismos causales, merece particular destaque la importancia de la disminución de la polarización de los sectores más pobres. Por lo general, los análisis sobre la estabilidad de la democracia no se concentran en el problema de la polarización del ingreso, y además es común que se analicen los efectos de la distribución del ingreso sobre la democracia, usando el Índice de Gini.

Este trabajo transitó un camino completamente distinto. En primer lugar, el énfasis en la polarización de ingresos es consecuencia del modelo teórico desarrollado, que abandona los supuestos del TVM, aplicados en importantes trabajos como los de Boix (2003) y Acemoglu y Robinson (2006). En segundo lugar, el énfasis en el problema de la polarización supuso abandonar el uso del Índice de Gini. Se elaboró entonces un Índice de Estabilidad Distributiva, que mide la disminución de la polarización de ingresos en los sectores más pobres.

El resultado, es que el IED predijo con mayor eficiencia que el Índice de Gini la duración de 65 regímenes democráticos durante el período 1945-2001. Asimismo, la expansión estable del producto también se encuentra asociada estadísticamente a la estabilidad democrática. Combinadas en una variable interacción, la disminución de la polarización y la expansión del producto también parecen afectar positivamente la duración de la democracia, este resultado anima a continuar la evaluación empírica del modelo teórico.

19 Boix (2003), por ejemplo, analiza la influencia de la movilidad de los factores productivos sobre la democracia, y consigue resultados relevantes, tanto desde el punto de vista teórico como empírico. La movilidad de los factores suele estar muy asociada al PBI per cápita -de hecho Boix utliliza en uno de sus modelos al PBI como medida de la propia movilidad de los factores-. En síntesis el PBI per cápita es una medida de riqueza relativa de una sociedad, pero está asociada con muchísima fuerza a numerosas dimensiones de la estructura económica de un país, aquí destacamos dos: la distribución del ingreso y la expansión del producto. 
Entonces: ipuede afirmarse a secas, como hace Lipset (1959), que el desarrollo capitalista favorece la democracia? Creo que no. Un análisis de conglomerados de 65 casos durante el período 1945-2001 ilustra claramente una realidad ya conocida: en algunas regiones del mundo el desarrollo capitalista estuvo asociado con altos niveles de renta, baja polarización y un crecimiento económico estable; mientras que en otras partes sucede todo lo contrario.

Las democracias del capitalismo central han sido completamente estables, no registran golpes de Estado y en el período considerado duraron en promedio 47 años. Las democracias periféricas, en cambio, sufrieron 11 interrupciones causadas por golpes de Estado, y la duración media de estos regímenes es de 18 años.

Pero además, las diferencias entre estos regímenes de acumulación capitalista (Boyer, 2007) se han visto reforzados por la dinámica de acumulación capitalista a nivel internacional. Desde el primer modelo de comercio internacional desarrollado por David Ricardo, hasta los más recientes desarrollados en la materia, todos coinciden en que el intercambio internacional hace que los países se especialicen en la producción de algunos bienes.

Esta especialización productiva se encuentra detrás de la polarización de ingresos y la inestabilidad en la expansión del producto, propias del capitalismo periférico (Cardoso y Faletto, 1969). Si entendemos al capitalismo como un sistema-mundo, entonces no es tan claro que el desarrollo capitalista haya favorecido a la democracia. El desarrollo dependiente es también un tipo de desarrollo capitalista, y el azaroso derrotero democrático de América Latina es una clara muestra de que la dinámica capitalista no siempre asegura democracia.

\section{REFERENCIAS}

Acemoglu, Daron y James Robinson. 2006. Economic Origins of Dictatorship and Democracy. New York:

Cambridge University Press.

Acemoglu et al. 2008. "Income and Democracy". American Economic Review 98 (3): 808-42.

Amin, Samir. 1976. La crisis estructural del capitalismo. Buenos Aires: Anagrama.

Aristóteles. 1984. La Política. Madrid: Alianza Editorial.

Boix, Carles. 2003. Democracy and redistribution. New York: Cambridge University Press.

Boyer, Robert. 2007. Crisis y regímenes de crecimiento: una introducción a la teoría de la regulación. Buenos Aires: Miño y Dávila.

Cardoso, Fernando Henrique y Enzo Faletto. 1969. Dependencia y desarrollo en América Latina; Ensayo de interpretación sociológica. México: Siglo Veintiuno Editores.

Diamond, Larry. 1993. "Reconsideración del nexo entre desarrollo económico y democracia". Estudios Públicos, Centro de Estudios Públicos Chile 49: 37-98.

Ferrer, Aldo, Raúl Prebisch y Celso Furtado. 1984. Para construir la democracia. Buenos Aires: El Cid Editor, Fundación para la Democracia en Argentina.

García Ferrando, Manuel. 1985. "Análisis y modelización causal en sociología". Revista española de investigaciones sociológicas. CIS, 143-164.

Groemling, Michael. 2002. "Why does redistribution not shrink when equality is high?". Intereconomics 204-211.

Hinich, Melvin J. y Michael C. Munger. 1997. Analytical politics. Cambridge-New York: Cambridge University Press. 
Kendall, Maurice y Allan Stuart. 1961. The advanced theory of statistics. London: Griffin.

Lipset, Seymour. 1959. [1992]. "Algunos requisitos sociales de la democracia: desarrollo económico y legitimidad política". En Diez textos básicos de ciencia política, editado por A. Batlle. Barcelona: Ariel, $113-150$.

Londregan, John B., and Keith T. Poole. 1996. "Does High Income Promote Democracy?". World Politics 49: 1-30.

Maddison, Angus. 2003. World Economy Historical Statistics. Paris: OECD.

Mainwaring, Scott y Aníbal Pérez-Liñan. 2006. "Nivel de desarrollo y democracia: el excepcionalismo latinoamericano (1945-1996)". En América Latina Hoy 36: 189-248.

Meltzer, Allan, y Scott F. Richard. 1981. "A Rational Theory of the Size of Government". Journal of Political Ecoomy 89 (5): 914-927.

Midlarsky, Manus I. 1997. Inequality, democracy, and economic development. Cambridge, UK; New York: Cambridge University Press.

Muller, Edward N. 1995. "Economic Determinants of Democracy". American Sociological Review.

O'Donnell, Guillermo A. 1982. 1966-1973, el Estado Burocrático Autoritario: triunfos, derrotas y crisis. Buenos Aires: Editorial de Belgrano.

ONU-WIDER, World Institute for Development Economics Research of the United Nations University. 2008. “World Income Inequality Database V2.0c May 2008”. [En línea] http:/ / www.wider.unu.edu/ research/Database/en_GB/database/, [Consulta: 1-5-2010].

Prebisch, Raúl. 1967. Hacia una dinámica del desarrollo latinoamericano. Montevideo: Ediciones de la Banda Oriental.

Przeworski, Adam et al. 2000. Democracy and development: political institutions and well-being in the world, 1950-1990. New York: Cambridge University Press.

Przeworski, Adam. 2004. "The Last Instance: Are Institutions the Primary Cause of Economic Development?". European Journal of Sociology 45 (2): 165-188.

Przeworski, Adam. 2005. Self-enforcing Democracy. Working Paper, Department of Politics. New York: New York University.

Rueschemeyer, D., Evelyne Huber Stephens y John Stephens. 1992. Capitalist Development and Democracy. Chicago: University of Chicago Press.

Traversa, Federico 2007. "Nuevo análisis de las precondiciones económicas de la democracia". Revista Uruguaya de Ciencia Política 16 (1): 103-129.

Wright, Erik 1983. Clase, crisis y Estado. México: Siglo XXI.

Wucherpfennig, Julian y Franziska Deutsch. 2009. “Modernization and Democracy: Theories and Evidence Revisited". Living Reviews in Democracy, Vol 1. [En línea] http:/ /www.democracy.livingreviews. org, [Consulta: 1-3-2010].

Federico Traversa es docente e investigador de la Universidad de la República, Uruguay. 